\title{
The effect of various root canal sealers on India ink and different concentrations of methylene blue solutions
}

\author{
Meltem Dartar Öztan ${ }^{\S}$ Ebru Özgey ${ }^{\S}$ Lale Zaimoğlu ${ }^{\S}$ and Nevin Erk ${ }^{\dagger}$ \\ $\S$ Department of Endodontics, Faculty of Dentistry, Ankara University, Ankara, Turkey \\ ${ }^{\dagger}$ Department of Analytic Chemistry, Faculty of Pharmacy, Ankara University, Ankara, Turkey
}

(Received 21 February and 23 October 2001)

\begin{abstract}
In this study, the effect of different root canal sealers on $1 \%$, and $2 \%$ methylene blue (MB) solutions and India ink were analyzed using spectrophotometry. One hundred and twelve specimens were used in this study. One hundred and five plastic tubes were filled with Sealapex, Endomethasone, Sultan, AH Plus or Ketac Endo. Twenty-one plastic tubes were used for each group. Seven plastic tubes were not filled, serving as controls. Seven specimens were taken from each group randomly and immersed in $0.8 \mathrm{ml} 1 \% \mathrm{MB}$, $2 \%$ MB or black India ink. The optical density of the solutions after $0,24,48$ and 72 hours of immersion was measured in a spectrophotometer at $416 \mathrm{~nm}$. The optical density (OD) of the solutions was stable for the control group. The OD values for the $1 \% \mathrm{MB}$ solutions were increased in the Sealapex and Sultan groups. The OD values for the $2 \%$ MB solutions were also increased for Sealapex and AH Plus. OD values were decreased for all India ink groups. The change in OD values relating to each time interval was statistically analyzed for each test material using two-way ANOVA. In the dye leakage studies, India ink, when compared to MB solutions, was a more reliable tracer as no dissolution of the root canal sealers occurred in contact with India ink. (J. Oral Sci. 43, 245-248, 2001)
\end{abstract}

Key words: root canal sealers; methylene blue; India ink.

Correspondence to Dr. Meltem Dartar Öztan, Karyağdı Sokak, No: 17/4, Çankaya Ankara, Turkey

Tel: +90-312-212 $6250 / 369,+90-312-4423494$

Fax: +90-312-212 3954

E-mail address: mdartar@hotmail.com

\section{Introduction}

Success and failure in endodontic therapy are considered to be dependent on the effectiveness of debridement and obturation of the root canal system. Complete debridement is necessary to remove all toxic products that cause periapical disease (1). The apical seal should prevent tissue fluid microcirculation between the root canal and periapical tissues, since tissue fluid could act as a substrate for microorganisms, which in many instances are left in the root canal even after thorough root canal debridement (2).

Numerous studies, using various techniques, have been performed to quantitatively assess the leakage potential of root canal filling materials (3). A commonly applied method to evaluate the sealing ability of different root filling materials and techniques is based on linear measurement of dye penetration between the root filling and the canal wall. Tracers such as methylene blue (MB), procion blue, eosin red, silver nitrate and India ink have been used $(4,5)$. Methylene blue, in various concentrations has been the most commonly used tracer for several decades, but over the last few years the number of studies using India ink have increased (6). Wu and Wesselink (7) reported that India ink was used mostly with the clearing technique that produced the lowest values of dye penetration, as compared to longitudinal splitting and horizontal section. In dye penetration experiments, one end of the filled specimen is immersed in a dye solution. Longitudinally splitting or cross sectioning the filled specimen at the end of the immersion period allows the length of colored dye penetration along the tooth/ filling junction to be measured. However, during the experiment the dye may be decolored, depending upon the chemical properties of the test materials in contact. Consequently, penetration of the decolored dye solution along the filling 
may not be seen, making the recorded length of dye penetration unreliable (8). The purpose of this study was to evaluate the effect of different root canal sealers on $1 \%$ and $2 \% \mathrm{MB}$ solutions and India ink, by using spectrophotometry.

\section{Materials and Methods}

This study was performed using a method described by Wu et al. (8). One hundred and twelve plastic tubes, of 1 $\mathrm{mm}$ wall thickness, $1.5 \mathrm{~mm}$ inner diameter and approximately $10 \mathrm{~mm}$ long, were used. The root canal sealers tested were calcium hydroxide based Sealapex (Kerr, Romulus, MI, USA), paraformaldehyde containing Endomethasone (Septodont 94100 Saint-Mour, France), zinc oxide eugenol based Sultan (Sultan Chemists, Inc. Englewood, NJ), polymer based AH Plus (Dentsply, De Trey, Weybridge, Surrey, UK) and glass ionomer based Ketac Endo (ESPE, Seefeld/Oberbay, Germany). Twenty-one plastic tubes were used for each group. Test materials were mixed according to the manufacturer's recommendations and the plastic tubes were filled using a lentulo spiral carrier in a low speed handpiece running at moderate speed. Seven plastic tubes were not filled, serving as controls. The tubes were stored for $48 \mathrm{~h}$ at $37{ }^{\circ} \mathrm{C}$ and $100 \%$ humidity to allow the sealers to set before immersion into dye solutions.

Table 1 Mean \pm S.D. optical density of $1 \%$ methylene blue after immersion at 0,24,48 and 72 hours

\begin{tabular}{|l|l|l|l|l|}
\hline Material & $\mathbf{0 ~ h r}$ & $\mathbf{2 4} \mathbf{~ h r}$ & $\mathbf{4 8} \mathbf{~ h r}$ & $\mathbf{7 2} \mathbf{~ h r}$ \\
\hline Sealapex & $0,921 \pm 0,003$ & $0,993 \pm 0,002$ & $1,083 \pm 0,048$ & $1,001 \pm 0,008$ \\
\hline Endomethasone & $1,488 \pm 0,007$ & $0,932 \pm 0,007$ & $0,715 \pm 0,008$ & $0,661 \pm 0,002$ \\
\hline Sultan & $0,922 \pm 0,006$ & $0,942 \pm 0,003$ & $0,982 \pm 0,005$ & $0,993 \pm 0,004$ \\
\hline AH Plus & $1,462 \pm 0,003$ & $1,208 \pm 0,004$ & $1,009 \pm 0,006$ & $0,895 \pm 0,003$ \\
\hline Ketac Endo & $0,690 \pm 0,008$ & $0,684 \pm 0,006$ & $0,567 \pm 0,006$ & $0,413 \pm 0,009$ \\
\hline Control & $0,545 \pm 0,008$ & $0,538 \pm 0,015$ & $0,525 \pm 0,012$ & $0,509 \pm 0,015$ \\
\hline \multicolumn{4}{|c|}{$\mathrm{F}_{\text {Group }}=6730,873 \quad \mathrm{~F}_{\text {Time }}=12375,851 \quad \mathrm{~F}_{\text {Time* Group }}=41,002$} \\
\hline
\end{tabular}

Table 2 Mean \pm S.D. optical density of $2 \%$ methylene blue after immersion at $0,24,48$ and 72 hours

\begin{tabular}{|l|l|l|l|l|}
\hline Material & $\mathbf{0 ~ h r}$ & $\mathbf{2 4} \mathbf{~ h r}$ & $\mathbf{4 8} \mathbf{~ h r}$ & $\mathbf{7 2} \mathbf{~ h r}$ \\
\hline Sealapex & $1,233 \pm 0,037$ & $1,315 \pm 0,009$ & $1,411 \pm 0,005$ & $1,510 \pm 0,004$ \\
\hline Endomethasone & $1,309 \pm 0,006$ & $1,057 \pm 0,051$ & $0,984 \pm 0,003$ & $0,877 \pm 0,004$ \\
\hline Sultan & $0,992 \pm 0,004$ & $0,826 \pm 0,024$ & $0,783 \pm 0,003$ & $0,611 \pm 0,006$ \\
\hline AH Plus & $1,562 \pm 0,017$ & $1,617 \pm 0,004$ & $1,782 \pm 0,009$ & $1,814 \pm 0,004$ \\
\hline Ketac Endo & $0,499 \pm 0,041$ & $0,406 \pm 0,009$ & $0,343 \pm 0,017$ & $0,292 \pm 0,006$ \\
\hline Control & $0,558 \pm 0,019$ & $0,538 \pm 0 ; 026$ & $0,508 \pm 0,028$ & $0,498 \pm 0,028$ \\
\hline \multicolumn{4}{|c|}{ F Froup $^{-10252,570 \quad \text { F Time }_{\text {Time }}=390,701 \text { Group }}=28,397$}
\end{tabular}

Table 3 Mean \pm S.D. optical density of India ink after immersion at $0,24,48$ and 72 hours

\begin{tabular}{|l|l|l|l|l|}
\hline Material & $\mathbf{0 ~ h r}$ & $\mathbf{2 4} \mathbf{~ h r}$ & $\mathbf{4 8} \mathbf{~ h r}$ & $\mathbf{7 2} \mathbf{~ h r}$ \\
\hline Sealapex & $0,933 \pm 0,049$ & $0,720 \pm 0,016$ & $0,715 \pm 0,014$ & $0,719 \pm 0,013$ \\
\hline Endomethasone & $0,958 \pm 0,026$ & $0,869 \pm 0,024$ & $0,816 \pm 0,027$ & $0,718 \pm 0,032$ \\
\hline Sultan & $0,978 \pm 0,005$ & $0,876 \pm 0,004$ & $0,863 \pm 0,006$ & $0,719 \pm 0,004$ \\
\hline AH Plus & $0,855 \pm 0,021$ & $0,724 \pm 0,023$ & $0,672 \pm 0,008$ & $0,659 \pm 0,005$ \\
\hline Ketac Endo & $0,920 \pm 0,008$ & $0,871 \pm 0,004$ & $0,530 \pm 0,004$ & $0,486 \pm 0,004$ \\
\hline Control & $0,517 \pm 0,078$ & $0,501 \pm 0,068$ & $0,487 \pm 0,059$ & $0,477 \pm 0,052$ \\
\hline
\end{tabular}

Three groups were formed according to the dye solutions tested. Group I used freshly mixed solutions of $1 \% \mathrm{MB}$, group II used 2\% MB and in group III a newly purchased bottle of black India ink (Pelikan, Istanbul, Turkey) was used. The dye solutions were placed in small plastic containers which were $25 \mathrm{~mm}$ high and had an inner

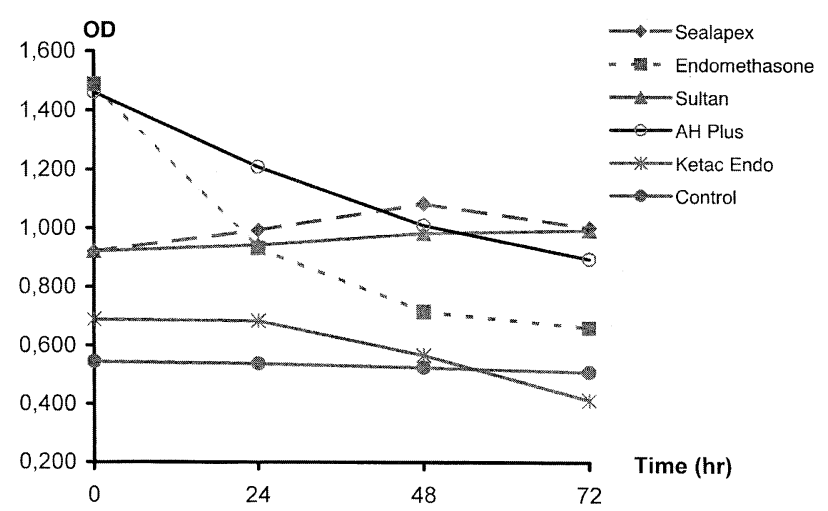

Fig. 1 Optical density change vs time graph for the $1 \%$ methylene blue group.

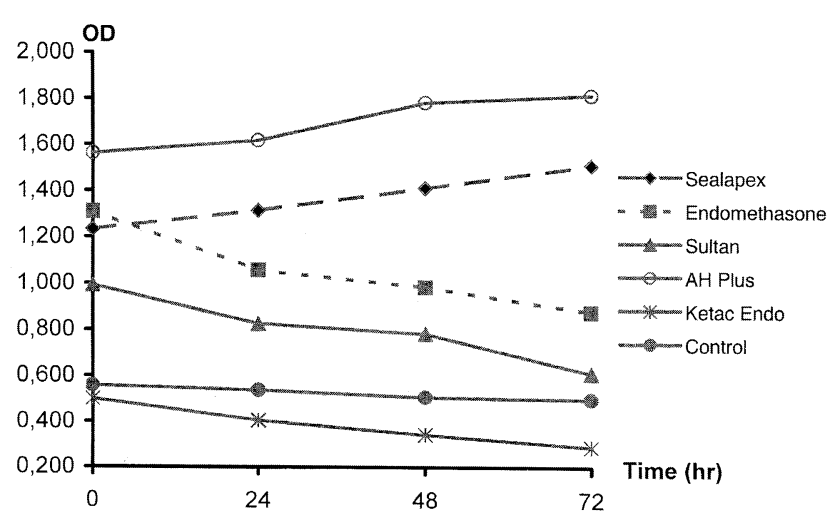

Fig. 2 Optical density change vs time graph for the $2 \%$ methylene blue group.

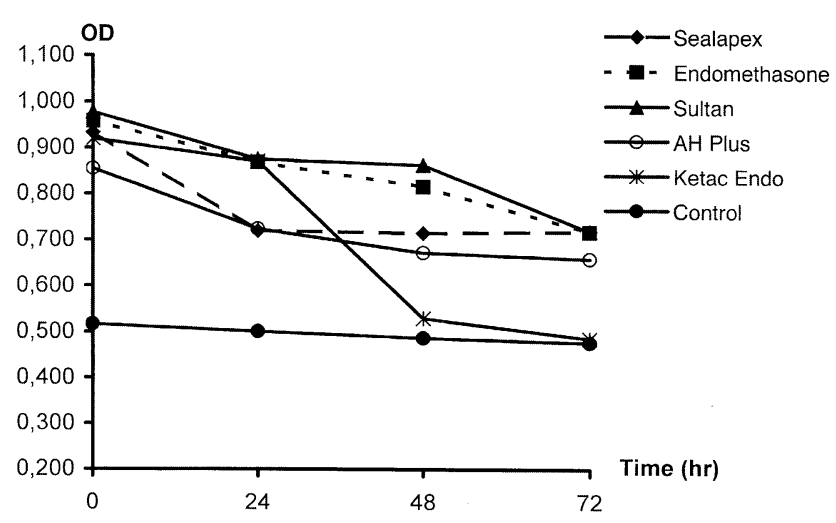

Fig. 3 Optical density vs time graph for the India ink group. 
diameter of $15 \mathrm{~mm}$. Seven tubes were taken randomly from each sealer group and immersed into plastic containers which contained $0.8 \mathrm{ml} \mathrm{1 \%} \mathrm{MB} \mathrm{(pH} \mathrm{7),} 2 \% \mathrm{MB}(\mathrm{pH} 7)$ or India ink. Samples $(0.1 \mathrm{ml})$ from each solution were taken from each container after 0 (immediately after immersion), 24, 48 and 72hours of immersion. Each sample was diluted with $1.9 \mathrm{ml}$ distilled water and the optical density measured using a 1601 UV-Vis spectrophotometer (Shimadzu, Japan) at $416 \mathrm{~nm}$. The change in OD values relating to each time interval was statistically analyzed for each test material using two-way ANOVA.

\section{Results}

The differences in the OD values between the test materials at different time intervals were statistically significant $(P<0.001)$ with all the three solutions. OD values were stable at all time intervals for the control group in all three solutions. The interaction of the test materials with time was also statistically significant $(P<$ $0.001)$. In all groups studied, the OD values were statistically significantly different between $0-24,24-48$ and 48-72 hours for each test solution $(P<0.001)$. The mean OD values of $1 \%$ and $2 \% \mathrm{MB}$ and India ink at 0 , 24, 48 and 72 hours are shown in Tables 1, 2 and 3.

\section{$1 \% \mathrm{MB}$ solution}

A continuous decrease was observed for the Endomethasone and AH Plus groups. In the Ketac Endo group the OD value was stable from 0-24 hours but decreased in the 24, 48 and 72 hours periods. In the Sealapex and Sultan groups, the OD value increased after 72 hours in comparison with the starting value (Fig. 1).

\section{$2 \% \mathrm{MB}$ solution}

OD values were increased in the Sealapex and AH Plus groups and decreased in the Ketac Endo, Endomethasone and Sultan groups (Fig. 2).

\section{India ink}

OD values were definitively decreased in the Sultan, Endomethasone, Ketac Endo and AH Plus groups. In the Sealapex group, the OD value showed a continuous decrease until 48hours, but between 48 and 72 hours an increase was observed (Fig. 3).

\section{Discussion}

The results taken from the spectrophotometric analysis used in this study indicated a reaction between the solution and the test materials. The decrease in the OD value signified a reduction in the concentration of the solution, whereas an increase in the OD value signified an increase in the concentration. An increase in the OD value indicated a chemical interaction in the structure of solution due to the solubility of the particles in the test materials and transfer to the solution. To determine which tracers are the most appropriate for investigation of microleakage it is important to understand their physical and chemical properties (9). In this study, 0 -hour samples were determined right after the plastic tubes containing sealers were immersed in to plastic containers, which contained the dye solutions. The period until the measurement was a neglectable period so the first measurement was defined as 0 hours. In the control group, the measurement was done by placing the empty plastic tubes in to the dye solution. In the experimental groups, the measurements were made immediately after the plastic tubes containing sealers were immersed in to the solution, so the first measurements obtained from the experimental groups were different from the one in the control group.

The calcium hydroxide based Sealapex and zinc oxide eugenol containing Sultan groups showed a continuous increase in the OD value of the $1 \% \mathrm{MB}$ solution. On the other hand, a continuous increase was observed in the OD value of the $2 \% \mathrm{MB}$ solution when Sealapex and AH Plus were used. These findings indicated that the root canal sealers mentioned above could dissolve while in contact with the MB solutions. Dissolution of root canal sealers creates a space between the root canal filling and the canal wall and this could render the recorded length of dye penetration as unreliable. Kontakiotis et al. (10) reported that $\mathrm{MB}$ solution was found to be decolored by calcium hydroxide, because MB is unstable with caustic alkali and hydrolyzed to transparent thional. Also, MB is blue in its oxidized form, which can be reduced and become colorless with reducing agents such as $\mathrm{Zn}, \mathrm{Cu}, \mathrm{Ag}$, etc. Therefore, ZOE can decolor the MB (8). On the other hand, in the present study, dissolution did not occur in the Endomethasone, AH Plus and Ketac Endo groups while in contact with the $1 \%$ MB solution. Similarly, in the $2 \%$ MB solution, dissolution was not observed in the Ketac Endo, Endomethasone or the Sultan groups. Therefore, it appears that the $1 \%$ and $2 \% \mathrm{MB}$ solutions are suitable tracers when used with the sealers mentioned above. In our study, AH Plus caused a continuous decrease in the OD of the $1 \% \mathrm{MB}$ whereas a continuous increase in the OD of the $2 \% \mathrm{MB}$. The interaction between the $2 \% \mathrm{MB}$ solution and chemical materials in the structure of AH Plus causes a transfer of some particles from the structure of sealer to the solution. The concentration of the dye solution is the cause of this difference. Based on these results, it can be concluded that in microleakage studies the use of $2 \% \mathrm{MB}$ with AH Plus may give misleading results. 
A decrease in the OD value was observed for the India ink for all time intervals and for all experimental groups. Although the OD values of Sealapex decreased continuously until 48hours, it increased between 48 and 72 hours. The OD value of Sealapex was 0.715 at $48 \mathrm{~h}$, whereas 0.719 at 72 hours and the difference of OD values between these time intervals was negligible. Since the OD value at $72 \mathrm{~h}$ was decreased in comparison with the starting value, it can be concluded that the OD values decreased in the India ink for the Sealapex group. The decrease in the OD value indicates the transfer of the particles from dye solution to the root canal sealer. As this does not create dissolution on the root canal sealer, linear measurement of dye penetration between the root filling and the canal wall will reflect real penetration. Çalışkan et al. (11) reported that a decolorizing effect of calcium hydroxide was not observed on India ink. In a recent in vitro study, investigating different tracers and assessment methods in the sealing ability of retrograde root fillings, it was noted that bacterial ingress and India ink penetration provided a similar rank order for the sealing ability of the material tested. It may be suggested that bacteria and India ink particles may detect similar microleakage channels being of broadly similar size, and thus will show similar degrees of penetration (12).

Ahlberg et al. (5) confirmed that an India ink solution is potentially a suitable tracer for microleakage and dentine permeability assessment. Other advantages of using India ink are that it does not stain the dentine and shows the leakage pattern only. In addition, the extent of dye penetration is easy to detect even in the dentinal tubules $(13,14)$. From the results of this study, it can be concluded that the recorded length of MB penetration in dye leakage studies may not always reveal the full length of the void along the filling, since some root canal sealers can significantly affect the MB solution. The results of this study support the use of India ink as a more reliable tracer in microleakage studies, which apply dye penetration methods, as no dissolution of the root canal sealers occur in contact with India ink.

\section{References}

1. Kersten, H.W. and Moorer, W.R. (1989) Particles and molecules in endodontic leakage. Int. Endod. J. 22, 118-124

2. Sjögren,U. and Sundqvist, G. (1987) Bacteriologic evaluation of ultrasonic root canal instrumentation. Oral Surg. Oral Med. Oral Pathol. 63, 366-370

3. Limkangwalmongkol, S., Abbott, P.V. and Sandler, A.B. (1992) Apical dye penetration with four root canal sealers and gutta-percha using longitudinal sectioning. J. Endod. 18, 535-539

4. Sevimay, S., Öztan, M., Özğey, E. and Zaimoǧlu, L. (1998) An evaluation of the effect of methylene blue dye $\mathrm{pH}$ on apical leakage. A.Ü Diş Hek Fak Derg. 25, 129- 136 (in Turkish)

5. Ahlberg, K.M.F., Assavanop, P. and Tay, W.M. (1995) A comparison of the apical dye penetration patterns shown by methylene blue and India ink in root-filled teeth. Int. Endod. J. 28, 30-34

6. Spangberg, L.S.W., Acierno, T.G. and Cha, B.Y. (1989) Influence of entrapped air on the accuracy of leakage studies using dye penetration methods. J. Endod. 15, 548-551

7. Wu, M.K. and Wesselink, P.R. (1993) Endodontic leakage studies reconsidered. Part I. Methodology, application and relevance. Int. Endod. J. 26, 37-43

8. Wu, M.K., Kontakiotis, E.G. and Wesselink, P.R. (1998) Decoloration of 1\% methylene blue solution in contact with dental filling materials. J. Dent. 26, 585- 589

9. Youngson, C.C., Jones, J.C., Manogue, M. and Smith, I.S. (1998) In vitro dentinal penetration by tracers used in microleakage studies. Int. Endod. J. 31, 90-99

10. Kontakiotis, E.G., Wu, M.K. and Wesselink, P.R. (1997) Effect of calcium hydroxide dressing on seal of permanent root filling. Endod. Dent. Traumatol. 13, 281-284

11. Çalişkan, M.K., Türkün, M. and Türkün, L.Ş. (1998) Effect of calcium hydroxide as an intracanal dressing on apical leakage. Int. Endod. J. 31, 173-177

12. Chong, B.S., Pitt Ford, T.R., Watson, T.F. and Wilson, R.F. (1995) Sealing ability of potential retrograde root filling materials. Endod. Dent. Traumatol. 11, 264-269

13. Smith, M.A. and Steiman, H.R. (1994) An in vitro evaluation of microleakage of two new and two old root canal sealers. J. Endod. 20, 18-21

14. Şen, B.H., Pişkin, B. and Baran, N. (1996) The effect of tubular penetration of root canal sealers on dye microleakage. Int. Endod. J. 29, 23-28 